DOI: http://doi.org/10.22585/hospdomic.v5i2.137

\title{
Las crisis, las oportunidades... y la hospitalización a domicilio
}

The crises, the opportunities... and the hospital-based home care services

Manuel Mirón Rubio' (1) 0000-0003-0440-6174

1. Presidente de la Sociedad Española de Hospitalización a Domicilio; Hospital Universitario de Torrejón, Servicio de Hospitalización a Domicilio, Torrejón de Ardoz, Madrid.

Correspondencia/Correspondence

Manuel Mirón Rubio

mmrubio@torrejonsalud.com

Recibido/Received

15.04 .2021

Aceptado/Accepted

15.04.2021

CÓMO CITAR ESTE TRABAJO | HOW TO CITE THIS PAPER

Mirón M. Las crisis, las oportunidades... y la hospitalización a domicilio. Hosp Domic. 2021;5(2):75-8. 
Todas las crisis, con independencia de su naturaleza e intensidad, ocasionan víctimas y secuelas. Cuando esas crisis se producen en el terreno de la salud, los afectados sufren enfermedades y, en casos extremos, la muerte. La pandemia por coronavirus es un claro ejemplo de cómo las crisis sanitarias representan una amenaza real para nuestra salud y para nuestras vidas.

Las crisis sanitarias también acostumbran a poner de manifiesto las carencias de los sistemas y servicios de salud. En periodos de estabilidad, percibimos una falsa sensación de poder y control sobre cada uno de los elementos que garantizan un acceso ordenado y de calidad a las prestaciones sanitarias. También aquí la covid-19 nos ha proporcionado una cura de humildad sin precedentes, al ponernos frente al espejo de la fragilidad de todos y cada uno de los eslabones que van desde la prevención hasta el intento de curación de las enfermedades.

Nunca antes la comunidad científica, acostumbrada a hacer uso y alarde de los más completos y complejos avances médicos, se había visto tan desconcertada por una enfermedad que ya desde su origen ha amenazado con tambalear alguno de los cimientos de la medicina moderna. El conocimiento científico se ha visto cuestionado, y la arrogancia de las sociedades denominadas avanzadas ha tenido que agachar la cabeza frente a la mayor crisis sanitaria, económica y social que ha conocido la humanidad en las últimas décadas: a fecha 23 de marzo de 2021, la OMS informaba más de 2 millones 700 mil muertes y 122 millones y medio de $\operatorname{afectados}^{(1)}$.

Sin embargo, estancarse en los aspectos negativos inherentes a cualquier crisis es impropio de la condición humana. Los humanos ya hemos dado repetidas muestras de nuestra capacidad de sobreponernos a las adversidades y de encontrar razones para la esperanza en medio de la desolación ${ }^{(2)}$. Esta cualidad - la resiliencia -, que lo es de la especie, no lo es, sin embargo, de todos los individuos por igual. Para algunos, las crisis representan una excusa para la inacción; para otros, son el punto de inflexión en el inagotable terreno de las oportunidades.

Como en otros muchos ámbitos de la sanidad - y de la vida en general -, los que llevamos años dedicándonos a la hospitalización a domicilio hemos sido testigos - a veces protagonistas - de esta dualidad de la condición humana. La crisis ha sido exigente para todos, pero unos han salido reforzados y otros debilitados.

Atribuir a la responsabilidad y decisiones de terceros las secuelas desfavorables que esta pandemia ha dejado en algunas unidades y servicios de hospitalización a domicilio sería un ejercicio de excesiva complacencia, necesario puede calmar la conciencia de algunos, pero inadecuado como estrategia de crecimiento profesional... y personal. El victimismo nos consuela, pero también nos paraliza. Quien no asuma que somos los artesanos de casi todas las estaciones de nuestro destino es que ha decidido instalarse en la comodidad de la inoperancia.

Sin embargo, sería injusto eximir a decisores y autoridades sanitarias de su responsabilidad en algunos de los episodios más indecorosos que nos ha dejado esta pandemia. Partiendo de la base de que no hay ningún sistema sanitario suficientemente preparado para soportar sin tensionarse una embestida de tal magnitud, las imágenes y testimonios de pasillos de hospitales con pacientes hacinados en condiciones inhumanas, las limitaciones para garantizar una muerte digna en casa, o las dificultades para facilitar un retorno precoz al entorno familiar de los pacientes con covid-19, obedece, en muchas ocasiones, a una falta de planificación y visión estratégica previas a la pandemia. Todo ello ha provocado, en ocasiones, un ineficiente uso de los recursos para atender a los pacientes más necesitados y un insoportable deterioro en la calidad asistencial. Para unos sistemas de salud que tanto han alardeado de políticas de humanización y de atención centrada en la persona, la pandemia ha venido a sonrojar a quienes hacen de la palabrería un modus vivendi.

Llevamos años informando, divulgando y publicando las ventajas que la hospitalización a domicilio representa para los pacientes y sus familias, para los hospitales y para los sistemas de salud. A los reconocidos efectos beneficiosos sobre los resultados en salud, se añaden las elevadas tasas 
de satisfacción de los usuarios y la mejora en la gestión de los recursos hospitalarios, y en especial, del recurso cama.

Quienes apostaron hace años con convicción por la transformación del modelo hospitalario hacia un modelo orientado a las necesidades y preferencias de los pacientes y la optimización de recursos, incorporando a su cartera de servicios la hospitalización a domicilio, han sido capaces de gestionar la pandemia con menos incertidumbre que los cicateros y los últimos de la fila. Los centros hospitalarios provistos con recursos de hospitalización a domicilio han maximizado la evitación de ingresos, la reducción de la estancia hospitalaria, la atención a pacientes en residencias y hoteles medicalizados, y la capacidad de ingresar a más pacientes con covid-19 atendiendo en sus casas a un mayor número de pacientes sin covid-19 ${ }^{(3,4)}$. La coordinación con Atención Primaria, con los servicios de Urgencias hospitalarios y con los profesionales de las plantas de hospitalización y de las residencias de mayores ha sido clave en este proceso.

Toda esta actividad ya ha generado evidencias sobre la utilidad de la hospitalización a domicilio en esta crisis ${ }^{(5,6)}$, ha permitido elaborar guías de actuación ${ }^{(7,8)}$, y es determinante en la identificación de factores de riesgo de mala evolución de los pacientes con infección por coronavirus atendidos en casa ${ }^{(3)}$. Por eso, todavía resulta más incomprensible que algunas organizaciones, aun disponiendo del recurso, hayan dejado pasar la oportunidad de aprovechar todo su potencial. Una vez más, la falta de convicción y de visión estratégica está detrás de las decisiones ineficientes.

Sin embargo, lo realmente importante no es lo que las organizaciones y profesionales han dejado de hacer, sino lo que se están dispuestos a hacer en adelante ${ }^{(9)}$. Si esta crisis ha servido para impulsar las conciencias de quienes todavía no habían contemplado la posibilidad de transformar el modelo hospitalario dominante, o de quienes necesitaban una justificación para hacerlo, entonces bienvenida sea.

Esa transformación debe ir encaminada a recuperar los valores de una medicina y unos sistemas sanitarios comprometidos con las necesidades y las preferencias de los pacientes y del acercamiento de los recursos al lugar donde los enfermos se sienten menos vulnerables. Este es el camino que propone y por el que aboga la Sociedad Española de Hospitalización a Domicilio; ese es el horizonte que justifica nuestro empeño; y ese es el propósito que mueve nuestras conciencias.

\section{BIBLIOGRAFÍA}

1. Organización Mundial de la Salud (OMS). Weekly Epidemiological Update on Covid-19. Ginebra, Suiza: OMS; 2021 (accedido 26 de marzo de 2021). Disponible en: https://bit.ly/3rFJnue

2. Echeverri D. Entre guerras y pandemias ¿volveremos a ser los mismos? ¿Hay duda de la resiliencia de la humanidad? Rev Colomb Cardiol. 2020;27(2):73-76. DOI: 10.1016/j.rccar.2020.04.003

3. Llorens P, Moreno-Pérez O, Espinosa B, García T, Payá AB, Sola S, et al. An integrated emergency department/hospital at home model in mild COVID-19 pneumonia: feasibility and outcomes after discharge from the emergency department. Intern Emerg Med. 2021;1-10. Online ahead of print. DOI: 10.1007/s11739-021-02661-8.

4. Nogués X, Sánchez-Martinez F, Castells X, Díez-Pérez A, Sabaté RA, Petit I, et al. Hospital-at-Home expands hospital capacity during COVID-19 pandemic. J Am Med Dir Assoc. 2021;S15258610(21)00139-0. Online ahead of print. DOI: 10.1016/j.jamda.2021.01.077

5. Ryan PP, Hawkins KL, Altman S, Granatowski L, Shy BD, Long J, et al. A novel virtual hospital at home model during the coronavirus disease 2019 (COVID-19) pandemic. Infect Control Hosp Epidemiol. 2020;1-3. Online ahead of print. DOI: 10.1017/ice.2020.435 
6. Sitammagari K, Murphy S, Kowalkowski M, Chou SH, Sullivan M, Taylor S, et al. Insights from rapid deployment of a "virtual hospital" as standard care during the COVID-19 pandemic. Ann Intern Med. 2021;174(2):192-9. DOI: 10.7326/M20-4076

7. Bryant PA, Rogers BA, Cowan R, Bowen AC, Pollard J; Hospital-in-the-Home Society Australasia. Planning and clinical role of acute medical home care services for COVID-19: consensus position statement by the Hospital-in-the-Home Society Australasia. Intern Med J. 2020;50(10):126771. DOI: $10.1111 /$ imj. 15011

8. Mujal Martínez A, Regalado de los Cobos J, Ruiz Castellano M, Mirón-Rubio M, Basterretxea Ozamiz A, Estrada Cuxart O, et al. Derivación a hospitalización a domicilio de pacientes con infección por COVID-19. Hosp Domic. 2020;4(2):59-67. DOI: 10.22585/hospdomic.v4i2.104

9. Coloma E, Nicolás D. Hospital at Home units in the post-COVID 19 era. Eur J Clin Invest. 2020;50(11):e13390. DOI: 10.1111/eci.13390 